Portland State University

PDXScholar

$5-24-2019$

\title{
Measuring the Association Between Perceived Stress and Incidence of Infectious Disease or Illness in College Students in Portland, OR
}

Trinity E. Joroski

Portland State University

Follow this and additional works at: https://pdxscholar.library.pdx.edu/honorstheses

Let us know how access to this document benefits you.

Recommended Citation

Joroski, Trinity E., "Measuring the Association Between Perceived Stress and Incidence of Infectious Disease or Illness in College Students in Portland, OR" (2019). University Honors Theses. Paper 769. https://doi.org/10.15760/honors.787

This Thesis is brought to you for free and open access. It has been accepted for inclusion in University Honors Theses by an authorized administrator of PDXScholar. Please contact us if we can make this document more accessible: pdxscholar@pdx.edu. 
Measuring the Association Between Perceived Stress and Incidence of Infectious Disease or Illness in College Students in Portland, OR by

Trinity Joroski

An undergraduate honors thesis submitted in partial fulfillment of there requirements for the degree of

Bachelor of Science

in

University Honors

and

Biology

Thesis Adviser

Claire Wheeler Ph.D

Portland State University

2019 
Measuring the Association Between Perceived Stress and Incidence of Infectious Disease or Illness in College Students in Portland, OR

\begin{abstract}
The purpose of this study was to measure the association between perceived stress and incidence of infectious disease or illness within a large participant group consisting primarily of local college students residing in Portland, Oregon. This was conducted using the widely used and well validated Perceived Stress Scale (PSS), which was distributed via social media platforms, various Portland State establishments such as the campus recreation center, in addition to reaching students by means of talking with professors and other peers. It was found that the condition regarding whether or not an individual missed class or work due to an illness, was the only condition that provided evidence of a statistical association between illness and perceived stress. We rejected the null hypothesis and accepted the hypothesized claim due to a t-test value of 0.054 .
\end{abstract}

\title{
Introduction
}

Stress is defined as "a state in which an animal, unable to adapt to one or more stressors, is no longer successfully coping with its environment and its wellbeing is compromised" (National Research Council, 2010, p.14). In the biological realm, as defined by The National Research Council, “stress denotes a real or perceived perturbation to an organism's physiological homeostasis or psychological well-being" (p.14). With this being said, it is known that essentially a great deal of research has been done in regards to whether or not stress plays a role 
in the dysregulation of the immune system. When described by scholars in this discourse, the research more often than not leans toward the strong possibility that a link between stress and vulnerability to illness is in fact a reality. Many studies have demonstrated that several bodily systems, such as the neuroendocrine and immune systems, work together to provide healthy and functioning anatomy. Any disruption to the stress response can result in possible imbalance of bodily physiology, later leading into "enhanced-susceptibility to infection and inflammatory or autoimmune disease" (Padgett \& Glaser, 2003, p. 445). My specific research focuses on perceived stress in college students, and asks whether or not this stress induces vulnerability to illness and disease. Perceived stress is essentially psychological stress, which is chiefly "determined by one's own perception of their stressfulness" (Cohen, Kamarck, \& Mermelstein, 1983). Psychological and/or emotional stress plays a large role in bodily function as written in an article which states that stress has been associated with two stress systems that affect immunity. These systems are the SAM (sympathetic adrenal-medullary system) and HPAC (hypothalamic-pituitary-adrenocortical system) systems which represent the "fight or flight" and "conservation-withdrawal" responses respectively (Oleary, 1990). Such research reinforces the theoretical link between stress and immunity, which when well-studied has been observed to play a substantial role in affecting the ability to multitask, cope and manage. As a college student, the author is well aware that many students have experienced high stress situations, a fair amount of which specifically pertain to academic stress and their ability to manage various pressing tasks. In a pilot study done by authors comparing Pharmacy and Doctor of Pharmacy (students studying for a doctorate in pharmaceutical practice) students, students were found to perceive stress related to program intensity. Immune-related diseases and health problems were 
more pronounced in the PharmD (Doctor of Pharmacy) students versus the Pharmacy students whose symptoms occurred mainly during exam periods. Notable symptoms included feelings of cold/ flu, skin problems and hair problems (Assaf, 2013). While academic stress is an overwhelmingly abundant source of stress, there is a range of categories describing perceived stress. For example, according to one article (Segerstrom \& Miller, 2004), there are five researched categories of stress. These are:

- Acute time-limited stressors (minor such as public speaking)

- Brief naturalistic stressors (exams)

- Stressful event sequences (loss of a spouse or natural disaster etc)

- Chronic stressors (force restructure of ones identity-severe)

- Distant stressors (occurred in past but have potential to continue modifying immune system)

All categories represent stressors that can impact the healthy physiology supporting the human body. To assess stress levels in participants, the widely used and well validated Perceived Stress Scale (PSS) survey, created in 1983 by Sheldon Cohen, at Carnegie Mellon University, was used (Cohen, Kamarck, \& Mermelstein, 1983). The PSS has been used in an abundance of research including that by Sribanditmongkol, Neal, Patrick, Szalacha, and McCarthy (2014), where a similar experiment was conducted focusing on cytokine-based responses to perceived stress. This study, like the current one, was done with healthy college students. Study design was based on the assumption that if a sufficient sample size of participants can be recruited for this study using the PSS, it would be possible to observe a statistically significant association between perceived stress and incident of infectious disease. Another premise of the study was that, depending on the 
effect size of perceived stress with respect to infectious disease risk in this population, it would be possible to test this hypothesis. The goal of this study was to recruit $100+$ participants, which was predicted to provide enough statistical power to observe what relationship, if any, exists between these two phenomena in students, community members, and general participants during the fall and winter terms in Portland, Oregon. It was predicted that recruitment may be hindered due to the lack of academic or financial incentives, however several studies of this type have been done without extrinsic incentives. In addition to survey instrument information, the online survey provided a platform for participants to provide input on what they would like to see changed or added to the stress relief programs available at the Portland State Center for Student Health and Counseling (SHAC).

\section{Methods}

Data were collected from members of the Portland State University community. An anonymous web based survey was used that consisted of fifteen questions total: fourteen multiple choice and one short answer item (see appendix I \& II, Fig. 4 \& 5). Demographic data were not collected in order to accrue a larger number of participants. The first ten questions of the survey consisted of PSS items. The subsequent five questions pertain specifically to individual health during the current or previous school term. The PSS items address circumstantial stress. For example, question one asks "In the last month, how often have you been upset because of something that happened unexpectedly?" The participant answers using a Likert scale of 0 through 4 , with 0 being not at all upset. An example of the remaining original questions is question number eleven, which asks "Did you come down with the flu or other form of illness during flu season (November-February) or in recent months?" Participants could 
answer this question with either "yes", "no", or "maybe." The final survey question is short answer and asked, "For PSU students: Portland State University Center for Student Health and Counseling (SHAC) wants to know, if you could add a resource to the stress-relief programs on campus, what would it be?" The data were analyzed for three conditions: whether or not the respondent reported having a cold or flu in the time period specified, whether or not they sought medical attention, and whether or not they missed classes or work because of the illness. Mean PSS scores in each of these three conditions were compared using 2- Sample T-tests. The goal of this analysis was to determine if there was a plausible link between stress and induced vulnerability to illness or disease in the surrounding community, specifically pertaining to PSU students. Due to the fact that the survey required the participation of human subjects, PSU's Institutional Review Board (IRB) was consulted. An exemption was granted, which allowed data collection to proceed without undergoing full IRB processing. The survey went online mid-March via various social media platforms including Facebook, Twitter and Snapchat, in addition to reaching out to various on campus resources for help with recruitment to the project. The Portland State Honors College agreed to have the survey placed in their weekly newsletter that is seen by hundreds of students, which greatly enhanced participation in the survey. Portland State Campus Recreation Center administrators agreed to help boost survey participation via various marketing tactics including advertising the survey on their social media platforms as well as strategically placing a recruitment flier around the recreation center. The flier (see appendix III, Fig.6) briefly summarized the project and contained a QR code which could easily be scanned, taking the participant directly to the survey created on Google Forms. 


\section{Results}

Table 1: Statistical values for each condition

\begin{tabular}{|l|lc|lc|ll|}
\hline Condition: Yes or No & \multicolumn{2}{|l|}{ Reported Sick } & \multicolumn{2}{l|}{ Medical Attention } & \multicolumn{2}{l|}{ Missed Class/Work } \\
\hline Mean PSS Score & Y: 21.9 & N: 22.5 & Y: 21.96 & N: 22.13 & Y:23.19 & N: 8.18 \\
\hline Standard Deviation & Y: 6.95 & N: 7.71 & Y: 5.85 & N: 7.47 & Y: 6.09 & N: 20.21 \\
\hline T-test value & 0.74 & 0.91 & & $\mathbf{0 . 0 5}$ \\
\hline
\end{tabular}

Table 2: Statistical PSS values for entirety of study

\begin{tabular}{|l|l|}
\hline Mean of PSS scores & 22.01 \\
\hline Standard Deviation of PSS scores & 7.28 \\
\hline
\end{tabular}


Did you come down with the flu or other form of illness during flu season (November-February) or in recent months?

102 responses

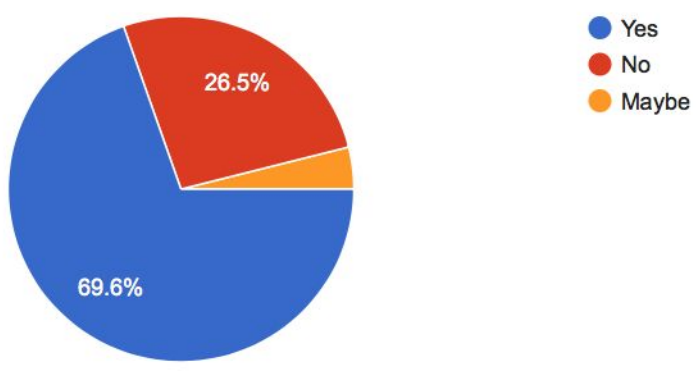

Figure 1: Graph showing results for first condition

Did you have to go to the doctor because of this illness?

102 responses

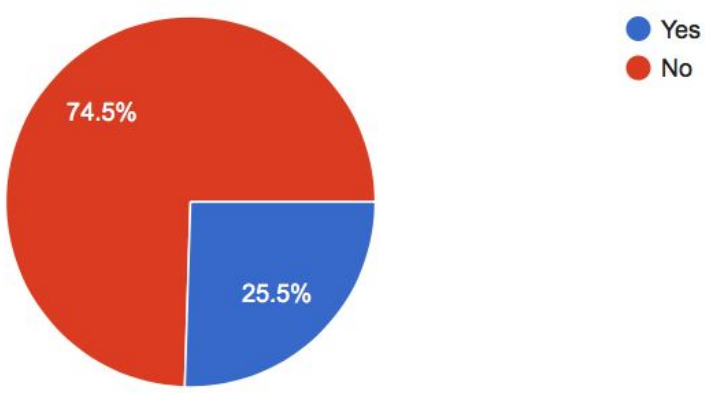

Figure 2: Graph showing results for second condition 


\section{Because of an illness in the last few months, have you had to miss work or school?}

102 responses
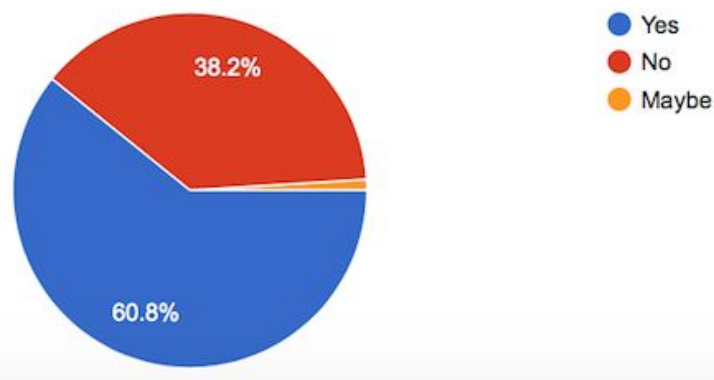

Figure 3: Graph showing results for third condition

\section{Discussion}

This project provided intriguing results. The original hypothesis was rejected for two conditions and was accepted for one. It had been hypothesized that all conditions would prove to be statistically significant, not one condition alone. This condition of whether or not an individual missed work or school due to an illness, was the only one significant for a few reasons. It is possible that certain participants may have felt somewhat under the weather and missed class or work to be safe, but perhaps did not mark themselves sick when taking the survey. People may have also missed class or work for other reasons associated with stress, such as an injury or some other form of emergency. Discrepancies such as these could have led to varying results that did not align with initial predictions. In addition, there are indeed a few sources of error that may have hindered my results. For example, the study did not ask for specific demographics such as age, sex, race, class etc. The participant pool was also made up of 
individuals who were students in addition to those who were not. Furthermore, the survey inquired about work and school, and did not focus on academics alone. Finally, selection bias may have been involved. There could have been any number of reasons that an individual chose to participate in my survey. Perhaps some individuals were already sick or already felt particularly stressed/not stressed when taking part. If this study were to be repeated, the nature of the demographics would be narrowed down in addition to allowing data collection to run for a longer period of time. In this way, more specific data could be acquired in addition to receiving a high number of participants. However, given that the data were taken from a broad and more generalized group of participants, it is this factor which sets this study apart from others that have already been done. Many studies observe a very specific grouping of individuals for their research. It is speculated that because the study offered a wider platform, the results reveal that perhaps a statistical association between perceived stress and vulnerability to illness may not be as straightforward as some literature presents. For example, a great deal of research done studies specific demographics of people who may even be predisposed to stress, illness, or both. In the experiment studying Doctor of Pharmacy and Pharmacy students (Assaf, 2013), the individuals taking part are constantly reading about illness and could even been exposed to people or patients with immune deficiencies, which could lead to results that reveal an association between the students' perceived stress and a degraded immune system. Another aim of this study was to not only attempt to observe an association between perceived stress and illness, but to also put focus on the need for better stress management and resources particularly at PSU. The results made it evident that improved resources would greatly benefit the student and community population. The PSS scale requires answers based on a Likert scale (0-4), meaning with 10 total 
PSS questions, if an individual were to answer all questions with an answer of 4 , the highest score possible is 40 . The observed specific average score based off the individuals that participated was a value of 22 . Since half of 40 is 20 , this value is above average, showing that there are more students who are stressed compared to those who are not. To put even greater emphasis on this issue, a question was asked which explored student feelings associated with the stress management resources at PSU, or more specifically the Center for Student Health and Counseling (SHAC). After asking what students would want to see changed or added to the stress management program at SHAC, a fair number of responses were recorded from people who were genuinely bothered by Portland State University's current program. For example, one individual stated that they would be happy to see "more culturally relevant and competent programs for people of color," while another individual stated there should not be a one term limit on counseling sessions at the center. In conclusion, there were a great deal of positives that can be taken away from this study in addition to learning what could have been done differently to observe a different outcome. With the great number of studies being continuously conducted, it is hopeful that this issue will be understood through a healthcare lens and seen as a public health issue in future studies to come. 


\section{Bibliography}

Assaf, A. M. (2013). Stress-induced immune-related diseases and health outcomes of pharmacy students: A pilot study. Saudi Pharmaceutical Journal, 21(1), 35-44.

Cohen, S., Kamarck, T., \& Mermelstein, R. (1983). A global measure of perceived stress. Journal of Health and Social Behavior, 385-396.

National Research Council. (2010). Recognition and alleviation of pain in laboratory animals (Vol. 1). Washington, DC., National Academies Press.

Oleary, A. (1990). Stress, emotion, and human immune function. Psychological Bulletin, 108(3), 363-382.

Padgett, D. A., \& Glaser, R. (2003). How stress influences the immune response. Trends in Immunology, 24(8), 444-448.

Segerstrom, S. C., \& Miller, G. E. (2004). Psychological stress and the human immune system: A meta-analytic study of 30 years of inquiry. Psychological Bulletin, 130(4), 601-630.

Sribanditmongkol, V., Neal J.L., Patrick T.E., Szalacha L.A., McCarthy D.O. (2014). Effect of perceived stress on cytokine production in healthy college students. Western Journal of Nursing Research, Vol. 37(4) 481-49. 


\section{Appendix I: PSS Question 1}

\section{Section 2 of 2}

\section{Perceived Stress Scale Survey}

The questions in this scale ask you about your feelings and thoughts during the last month. In each case, you will be asked to indicate by circling how often you felt or thought a certain way.

$0=$ Never $\quad 1=$ Almost Never 2 = Sometimes $3=$ Fairly Often $4=$ Very Often

In the last month, how often have you been upset because of something that happened unexpectedly?

0

1

2

3

4

Figure 4: PSS Question Regarding Stress 


\section{Appendix II: Survey Question 11}

Did you come down with the flu or other form of illness during flu season (November-February) or in recent months?
Yes
No
Maybe

Figure 5: Survey Question Regarding Health Status 
Appendix III: Marketing Flier

\section{Attention all Portland State students and members of the community!}

llave you over been stressed outep

Take a moment to fill out an anonymous survey as part of my thesis, so I can learn how SIIESS affects the human immune system!

SHAC wants to know too! How can we help our students?

Link: https://forms.gle/5CTchydB69M5GWfN9

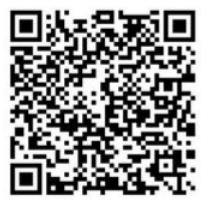

Survey \& Project by: Trinity Joroski \& Professor Claire Wheeler

Figure 6: Informational Flier Created for Marketing Purposes 